\title{
Article
}

\section{Evaluation of Fluid Loss and Customary Fluid Intake among a Selected Group of Young Swimmers: A Preliminary Field Study}

\author{
Damian Wiśniewski $^{1}$, Ewa Śliwicka ${ }^{2} \mathbb{D}$, Jakub Malik ${ }^{3} \mathbb{D}$ and Krzysztof Durkalec-Michalski ${ }^{1,4, *(\mathbb{D})}$ \\ 1 Department of Sports Dietetics, Poznan University of Physical Education, 61-871 Poznań, Poland; \\ wisniewski@awf.poznan.pl \\ 2 Department of Physiology and Biochemistry, Poznan University of Physical Education, \\ 61-871 Poznań, Poland; sliwicka@awf.poznan.pl \\ 3 Department of Physical Activity and Health Promotion Science, Poznan University of Physical Education, \\ 61-871 Poznań, Poland; malik@awf.poznan.pl \\ 4 Department of Human Nutrition and Dietetics, Poznan University of Life Sciences, 61-871 Poznań, Poland \\ * Correspondence: durkalec-michalski@awf.poznan.pl; Tel.: +48-61-835-52-87
}

check for updates

Citation: Wiśniewski, D.; Śliwicka, E.; Malik, J.; Durkalec-Michalski, K. Evaluation of Fluid Loss and Customary Fluid Intake among a Selected Group of Young Swimmers: A Preliminary Field Study. Int. J. Environ. Res. Public Health 2021, 18 3205. https://doi.org/10.3390/ ijerph18063205

Academic Editor: Michał Krzysztofik

Received: 23 February 2021

Accepted: 16 March 2021

Published: 19 March 2021

Publisher's Note: MDPI stays neutral with regard to jurisdictional claims in published maps and institutional affiliations.

Copyright: (C) 2021 by the authors Licensee MDPI, Basel, Switzerland This article is an open access article distributed under the terms and conditions of the Creative Commons Attribution (CC BY) license (https:/ creativecommons.org/licenses/by/ $4.0 /)$.

\begin{abstract}
This study aimed to assess fluid loss (FL) and customary fluid intake (FI) during a training session, and the relationship between FL and total body water (TBW) content in a selected group of young swimmers. The study involved 17 (seven females, 10 males) individuals whose anthropometric and body composition analyses and FI during training units were carried out. The total average FI and total actual FL oscillated around $531 \mathrm{~mL}$ and $-513 \mathrm{~mL}$ for the whole study group (469 $\mathrm{mL}$ and $-284 \mathrm{~mL}$ for females, $574 \mathrm{~mL}$ and $-674 \mathrm{~mL}$ for males). The dependent and independent sample t-tests, the Cohen's d effect size and Pearson's correlation coefficient were analysed. Significant differences were observed between pre-workout and post-workout body weights after training without FI in the whole group $(66.5 \mathrm{~kg}$ vs. $66.0 \mathrm{~kg}, p<0.001, \mathrm{~d}=0.06)$, in females $(61.2 \mathrm{~kg}$ vs. $60.9 \mathrm{~kg}$, $p=0.015, \mathrm{~d}=0.04)$ and males (70.3 kg vs. $69.6 \mathrm{~kg}, p<0.001, \mathrm{~d}=0.9)$. For the TBW content and fat-free mass (FFM) before and after training, significant differences were observed only in males (TBW: $43.8 \mathrm{~L}$ vs. $43.2 \mathrm{~L}, p=0.002, \mathrm{~d}=0.14$; and $62.4 \%$ vs. $61.7 \%, p<0.001, \mathrm{~d}=0.36$; FFM: $59.8 \mathrm{~kg}$ vs. $59.1 \mathrm{~kg}, p=0.002, \mathrm{~d}=0.12)$. Moreover, the relationship between the actual FL and TBW before training was observed in the whole (mL vs. \%: $\mathrm{r}=-0.64, p=0.006 ; \mathrm{mL}$ vs. L: $\mathrm{r}=-0.84, p<0.001$ ) and the male group ( $\mathrm{mL}$ vs. $\mathrm{L}: \mathrm{r}=-0.73, p=0.017$ ). These results indicated FL in young swimmers during training and the relationship between FL and pre-training TBW content, which suggests that it is important to also pay special attention to effective hydration procedures before and during training in aquatic environments.
\end{abstract}

Keywords: hydration; dehydration; body composition; training; young athletes; aquatic sports

\section{Introduction}

Swimming has been included in the Olympic disciplines since the first modern Summer Olympics, which took place in 1896 [1]. Currently, the swimming competitions are held in swimming pools of 50 and $25 \mathrm{~m}$ in length. The most important swimming competitions, e.g., during the Olympic Games or the World Championships, are held in a pool (the so-called "Olympic Pool") that is 50 (length) $\times 25$ (width) $\mathrm{m}$, a minimum of two meters deep and divided into 10 tracks. The water temperature should oscillate between 25 and $28{ }^{\circ} \mathrm{C}$ [2]. It should be noted that in an aquatic environment (such as in swimming disciplines), the human organism is subject to different environmental conditions than when it is on land. Among other things, it is affected by high hydrostatic pressure, which increases blood flow to the main body organs (brain, heart, lungs) and stimulates diuretic activity [3]. It remains unclear how the water environment (especially during exercise) influences sweating specificity. This can be crucial in sports because sweating is the most 
efficient mechanism for maintaining the optimal body temperature, and facilitating the removal of some metabolic products [4].

It should therefore be emphasised that proper hydration is vital because water in the human body, apart from its thermoregulatory role, also determines many other functions, such as transporting nutrients and giving structure to cells and tissues [5]. It is claimed that the human body in natural conditions could function without fluid intake (FI) for only two to four days [5]. Furthermore, it is estimated that the total body water (TBW) content in the human body oscillates on average around $59 \%$ in the case of men, and about $56 \%$ in the case of women [6], but these discrepancies are primarily related to body composition differences [7]. Moreover, in adolescents, TBW usually ranges from 49 to $63 \%$ in females and 52 to $66 \%$ in males, and these values decrease with age [8].

However, when the relationship between FI and FL (fluid loss) is unbalanced, dehydration may occur, such as a reduction in TBW due to FL, reduced FI or both [5]. It should be noted that dehydration may significantly and very quickly undermine the optimal functioning of the organism by, among others, deteriorating the mood, disrupting cognitive functions or reducing glycaemic regulation [9]. This condition may be a pathogenic factor in such diseases and conditions as hypertension, coronary artery disease or stroke [10]. Dehydration is also a serious problem in sport, impairing physical capacity and exercise performance in a wide range of disciplines [11-16]. It must be underlined that inadequate body hydration status leads to cardiorespiratory disturbances [17], a higher frequency of heart contractions at sub-maximum load [11], elevated lactate concentration during longterm efforts [12], a higher degree of perceived exercise load and lower power output during time trials [13], and lower maximum oxygen uptake $\left(\mathrm{VO}_{2} \mathrm{max}\right)$ [14] in exercising subjects.

Finally, the problem of dehydration risk seems to be crucial in young people. The prevalence of inadequate hydration status among 4134 participants aged 6 to 19 years even reached $54.5 \%$ [18]. The severity of this problem can be exacerbated by environmental conditions such as high temperature. Research conducted in Cyprus revealed that ninety percent of the adolescents (141 participants aged 15 to 17 years) arrive customarily dehydrated at school [19]. This issue is also observed in young athletes in different sports (including young swimmers) [20,21]. For example, Adams et al. [21] tested osmolality and specific gravity in morning urine samples, and recorded that $67 \%$ of young swimmers started their first training unit in an inadequate state of hydration. Demonstrated irregularities in hydration status may lead to negative exercise and health consequences [22], which proves the need to conduct research in this area. In our studies, we hypothesised that the FI during usual training units would be low, which would result in a significant reduction in body mass due to FL related to exercise-induced thermoregulatory activity. For these reasons, this study aimed to assess (1) fluid loss (FL) and customary fluid intake (FI) during a training session, and (2) the relationship between FL and total body water (TBW) content in a selected group of young swimmers.

\section{Materials and Methods}

\subsection{Participants}

The study was conducted with a group of 17 swimmers (seven females (body height: $166 \pm 4.3 \mathrm{~cm}$; body mass: $61.2 \pm 6.4 \mathrm{~kg}$; body mass index: $22.2 \pm 1.7$ ) and 10 males (body height: $179 \pm 4.6 \mathrm{~cm}$; body mass: $70.3 \pm 7.4 \mathrm{~kg}$; body mass index: $21.9 \pm 1.4)$, Figure 1). Participants were aged 15 to 17 years $(16.4 \pm 0.6$ years $)$ at the time of inclusion. Their training experience was about nine years. The studied swimmers were of a Caucasian race. They were members of a ZSMS Poznan swimming club and were competing in national sport competition in the junior category. 


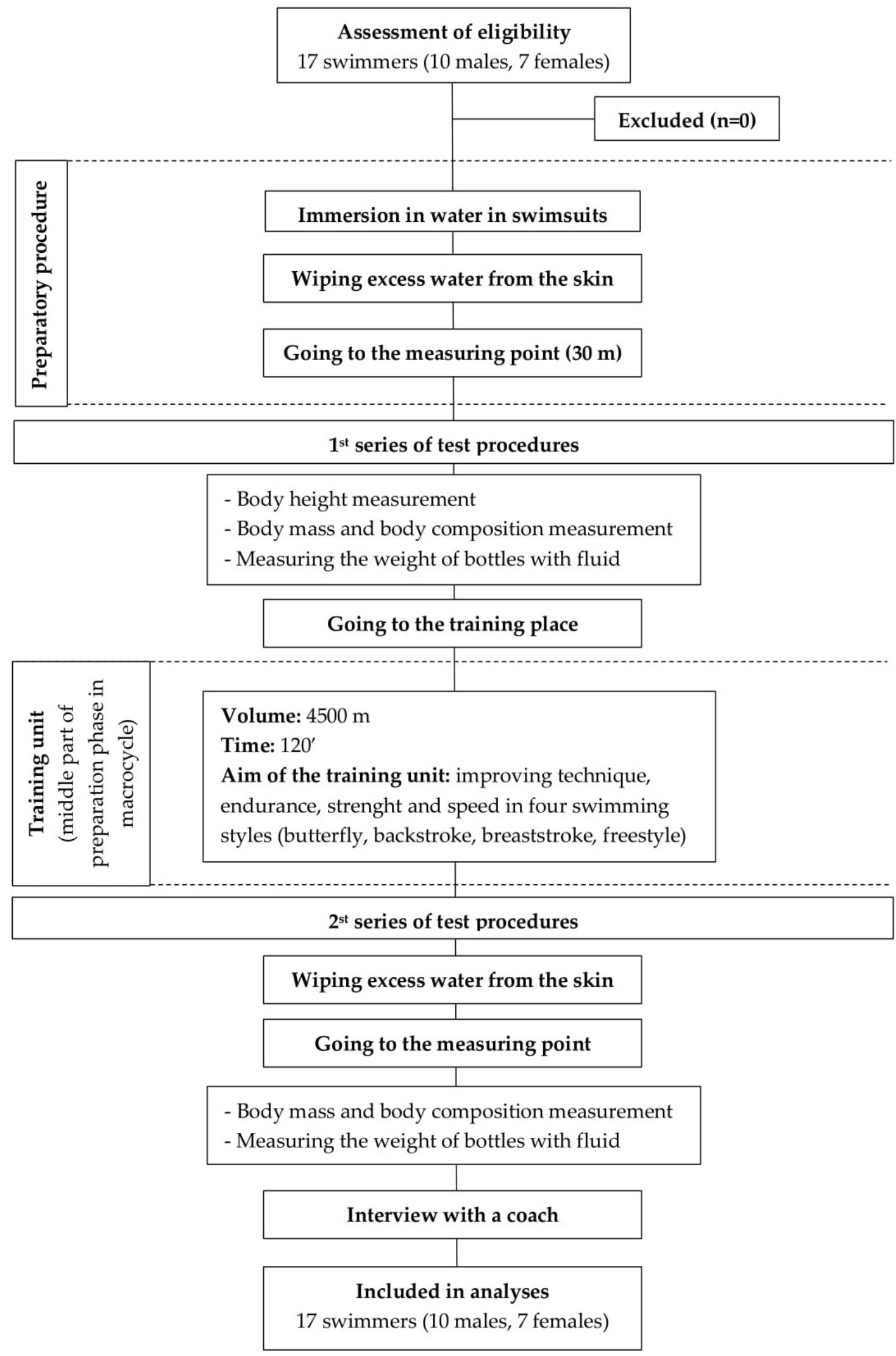

Figure 1. A flow chart of the study design. 
Participation in the study was voluntary; participants were informed about the purpose of the study and could withdraw at any time. An ethical review and approval were waived for this study due to the non-interventional and non-invasive status of this observational preliminary study. The test protocol was conducted in accordance with the ethical standards of the Helsinki Declaration and all participants and their parents gave informed consent to their participation.

\subsection{Training Characteristics}

The athletes performed seven units of classic swimming training and three combined units (i.e., strength training in the gym and then swimming) as standard during the week. This gave an average of about $22.5 \mathrm{~h}$ of training and about $50 \mathrm{~km}$ of distance covered in the water during the week-long training period. The micro-cycle in which the test was performed took place in the middle of the general preparation period, two months before the first competition held in April that year.

The training unit during which the test took place lasted two hours. During this time, the athletes had to swim a distance of $4500 \mathrm{~m}$, performing exercises to improve technique, endurance, strength and speed in the four most important swimming styles (butterfly, backstroke, breaststroke and freestyle).

\subsection{Procedures}

The study took place in February 2018 at the Olympic swimming pool, during the second swimmer training unit on that day, held between 4 and 6 p.m. The water and air temperature were $27^{\circ} \mathrm{C}$.

After enrolment, the study started with collecting basic information from the young swimmers (name, surname, age). Then, they were asked to immerse themselves in the pool water (so that their swimsuits and hair were soaked in water) and wipe themselves off in order to remove the excess water from their bodies. The next step was to move to a medical room ( $30 \mathrm{~m}$ away), where the height, weight and composition of the body were measured and drink bottles weighed. After the measurements were taken, the competitors went to train. After the training unit, athletes were asked to wipe themselves off again and go to the medical room where the second weight and body composition measurement took place and the drink bottles were weighed again. After the second measurement was taken, information was collected from the swimmers' coach about the training registration details performed by the athletes. A flow chart of the study design is presented in Figure 1.

\subsection{Body Mass and Composition Analysis}

Body height was measured using an anthropometer (GPM, Zurich, Switzerland). The body weight (BW) and composition (bioimpedance analysis, BIA) of the athletes were measured with the single-frequency $(50 \mathrm{kHz}, 90 \mu \mathrm{A})$ and multi-segmental TANITA BC-418 MA analyser (Tokyo, Japan). This analyser allows for precise measurements within the age range of 7 to 99 years. The same device was used throughout the entire study. After the sex, age and height data were entered into the TANITA BC-418 MA device, swimmers were asked to stand of the weighting platform (upright position) with bare feet. Their toes and heels were contacted with the electrodes of the platform. Afterwards, the participants grasped the device grips with electrodes with both hands and the measurements began. Body composition indices were estimated using the manufacturer's inbuilt algorithm utilizing regression formulas based on weight, height, age, sex and whole-body resistance. The measurements detected by used device included indicators such as weight, body fat percentage, fat mass, fat free mass, body water mass, and impedance. Furthermore, the test-retest reliability for whole-body lean body mass and body fat percentage estimates were $\geq 0.945$ using the intra-class correlation coefficient.

Drink bottles were weighted using a certified kitchen scale (CLATRONIC KW 3366, accuracy up to $1 \mathrm{~g}$ (Kempen, Germany)). In order to avoid any bias resulting from changing the person doing the measurement, the same person evaluated pre- and post-training mea- 
surements. During the training unit, swimmers could drink ad libitum the carbohydrate hypotonic drink (3\%) UNISPORT, made by Nutrend (Olomouc, Czech Republic). The athletes did not eat solid food. In order to compensate for factors that may affect the difference between the first and second weight measurements other than training, the athletes submerged themselves in the pool water so that their swimsuits and hair were soaked in water. They were also asked not to use the toilet between weight measurements. Due to a possible abnormal bioimpedance analysis result, $24 \mathrm{~h}$ before training, athletes were required not to consume alcohol or caffeine. By adjusting swimmers' BW after training to the amount of fluids they consumed, the actual value of changes in BW that would have occurred after training if swimmers had not consumed fluids during training was also calculated. By subtracting the swimmers' BW from this value before training, the amount of swimmers' FL during the training unit was obtained.

\subsection{Statistical Analysis}

The results, presented as means and standard deviations (SD), were analysed using an Excel sheet, which is part of the MS 2015 package (Microsoft, Washington, DC, USA) and Statistica 13.3 software (StatSoft Inc., Tulsa, OK, USA). The normality of data distributions was checked by the Shapiro-Wilk test. A $t$-test for dependent samples was used to detect statistically significant differences between pre-training and post-training results, while a $t$ test for independent samples was used to detect differences between females' and males' FI and FL. Relationships between selected variables were demonstrated by using the Pearson correlation coefficient $r$. Statistical significance for all analyses was established at the level of $95.0 \%(p<0.05)$. The effect size by d Cohen $(0.2$ to 0.5 - small effect, 0.5 to 0.8 -medium effect, 0.8 to 1.3-large effect, > 1.3-very large effect) was used to complete the statistical inference for individual comparisons (G*Power 3.1.9.6; Franz Faul, Universität Kiel, Kiel, Germany) [23].

\section{Results}

The results concerning usual FI and actual FL for the whole study group are presented in Table 1 . These values were presented to deepen the interpretative possibilities per hour $(\mathrm{mL} / \mathrm{h})$, minute $(\mathrm{mL} / \mathrm{min}), 1000 \mathrm{~m}(\mathrm{~mL} / 1000 \mathrm{~m})$ and per kilogram of $\mathrm{BW}$ per hour $(\mathrm{mL} / \mathrm{kg} / \mathrm{h})$. Significant gender differences between female and male group were revealed in FL (females vs. males: $-284 \mathrm{~mL}$ vs. $-674 \mathrm{~mL}(p=0.004, \mathrm{~d}=1.73),-142 \mathrm{~mL} / \mathrm{h}$ vs. $-337 \mathrm{~mL} / \mathrm{h}(p=0.004, \mathrm{~d}=1.69),-63 \mathrm{~mL} / 1000 \mathrm{~m}$ vs. $-150 \mathrm{~mL} / 1000 \mathrm{~m}(p=0.004$, $\mathrm{d}=1.7),-2.2 \mathrm{~mL} / \mathrm{kg} / \mathrm{h}$ vs. $-4.8 \mathrm{~mL} / \mathrm{kg} / \mathrm{h}(p=0.006, \mathrm{~d}=1.61)$, and $-4.7 \mathrm{~mL} / \mathrm{min} \mathrm{vs}$. $-11.2 \mathrm{~mL} / \mathrm{min}(p=0.004, \mathrm{~d}=1.69)$; Table 1$)$. Furthermore, the total average FI and total actual FL were about $531 \mathrm{~mL}$ and $-513 \mathrm{~mL}$, respectively, for the whole study group. Some noticeable but insignificant gender differences were observed in this respect (FI vs. FL: $469 \mathrm{~mL}$ and $-284 \mathrm{~mL}$ for females; $574 \mathrm{~mL}$ and $-674 \mathrm{~mL}$ for males). In addition, no intergender dependence was observed in FI.

The results concerning BW (before and after exercise with and without fluid intake), TBW, fat free mass (FFM), fat mass (FM) for the whole group, for females and males are presented in Table 2. The results show the values measured in the participants before and after the training unit. Significant differences were observed between BW before and after training without taking fluids for the whole group $(66.5 \mathrm{~kg}$ vs. $66.0 \mathrm{~kg}, p<0.001$, $\mathrm{d}=0.06$; Table 2), females (61.2 kg vs. $60.9 \mathrm{~kg}, p=0.015, \mathrm{~d}=0.04$; Table 2) and males (70.3 kg vs. $69.6 \mathrm{~kg}, p<0.001, \mathrm{~d}=0.91$; Table 2 ). For TBW and FFM before and after training, significant differences were observed only in males (TBW: $43.8 \mathrm{~L}$ vs. $43.2 \mathrm{~L}, p=0.002$, $\mathrm{d}=0.14$ and $62.4 \%$ vs. $61.7 \%, p<0.001, \mathrm{~d}=0.36$; FFM: $59.8 \mathrm{~kg}$ vs. $59.1 \mathrm{~kg}, p=0.002, \mathrm{~d}=0.12$; Table 2).The weight of adipose tissue differed after training in the whole group (12.5 kg vs. $12.9 \mathrm{~kg}, p=0.032, \mathrm{~d}=0.11$; Table 2) and in the group of males (10.5 kg vs. $11.1 \mathrm{~kg}, p<0.001$, $\mathrm{d}=0.24 ; 14.8 \%$ vs. $15.7 \%, p<0.001, \mathrm{~d}=0.34$; Table 2). No significant differences in FM before and after training were observed in the females' group. 
Table 1. Fluid intake and actual fluids loss in the whole group, female and male.

\begin{tabular}{|c|c|c|c|c|c|c|c|c|c|}
\hline \multirow[t]{2}{*}{ Variable } & & \multirow{2}{*}{$\begin{array}{l}\text { All }(n=17) \\
\text { Mean } \pm \text { SD }\end{array}$} & \multicolumn{3}{|c|}{$\begin{array}{c}\text { Females } \\
(n=7)\end{array}$} & \multicolumn{2}{|l|}{$\begin{array}{c}\text { Males } \\
(n=10)\end{array}$} & \multirow{2}{*}{\begin{tabular}{c}
\multicolumn{1}{c}{$p$-Value ${ }^{\wedge}$} \\
Females vs. Males
\end{tabular}} & \multirow{2}{*}{$\begin{array}{c}\text { Cohen's d Effect Size } \\
\text { Females vs. Males }\end{array}$} \\
\hline & & & Mean & \pm & SD & Mean \pm & SD & & \\
\hline \multirow{5}{*}{ Fluid intake } & $\mathrm{mL}$ & $531 \pm 322$ & 469 & \pm & 310 & 574 & 340 & 0.525 & 0.3227 \\
\hline & $\mathrm{mL} / \mathrm{h}$ & $266 \pm 161$ & 235 & \pm & 155 & 287 & 170 & 0.525 & 0.3197 \\
\hline & $\mathrm{mL} / 1000 \mathrm{~m}$ & $118 \pm 72$ & 104 & \pm & 69 & 128 & 76 & 0.525 & 0.3306 \\
\hline & $\mathrm{mL} / \mathrm{kg} / \mathrm{h}$ & $4.1 \pm 2.4$ & 3.9 & \pm & 2.5 & 4.2 & 2.5 & 0.810 & 0.1200 \\
\hline & $\mathrm{mL} / \mathrm{min}$ & $8.9 \pm 5.4$ & 7.8 & \pm & 5.2 & 9.6 & 5.7 & 0.525 & 0.3299 \\
\hline \multirow{5}{*}{ Actual fluids loss } & $\mathrm{mL}$ & $-513 \pm 300$ & -284 & \pm & 221 & $-674 \pm$ & 240 & 0.004 * & 1.7259 \\
\hline & $\mathrm{mL} / \mathrm{h}$ & $-257 \pm 150$ & -142 & \pm & 111 & $-337 \pm$ & 120 & 0.004 * & 1.6870 \\
\hline & $\mathrm{mL} / 1000 \mathrm{~m}$ & $-114 \pm 67$ & -63 & \pm & 49 & $-150 \pm$ & 53 & 0.004 * & 1.7046 \\
\hline & $\mathrm{mL} / \mathrm{kg} / \mathrm{h}$ & $-3.7 \pm 2.0$ & -2.2 & \pm & 1.8 & $-4.8 \pm$ & 1.4 & 0.006 * & 1.6125 \\
\hline & $\mathrm{mL} / \mathrm{min}$ & $-8.6 \pm 5.0$ & -4.7 & \pm & 3.7 & $-11.2 \pm$ & 4.0 & 0.004 * & 1.6870 \\
\hline
\end{tabular}

Values are expressed as means $\pm \mathrm{SD}$. ^ difference between two independent means-females vs. males. Effect size by d Cohen (0.2 to 0.5 -small effect, 0.5 to 0.8 -medium effect, 0.8 to 1.3 -large effect, $>1.3$-very large effect); ${ }^{*}$ statistically significant.

Table 2. Body mass and composition before (pre) and after (post) workout in the whole group, female and male.

\begin{tabular}{|c|c|c|c|c|c|c|c|c|c|c|c|c|c|c|c|}
\hline \multirow{2}{*}{\multicolumn{3}{|c|}{ Variable }} & \multicolumn{3}{|c|}{ All $(n=17)$} & \multicolumn{5}{|c|}{ Females $(n=7)$} & \multicolumn{5}{|c|}{ Males $(n=10)$} \\
\hline & & & Mean \pm SD & $p$-Value ^ & $\begin{array}{l}\text { Cohen's d } \\
\text { Effect Size }\end{array}$ & Mean & \pm & SD & $p$-Value ${ }^{\wedge}$ & $\begin{array}{l}\text { Cohen's d } \\
\text { Effect Size }\end{array}$ & Mean & \pm & SD & $p$-Value ^ & $\begin{array}{l}\text { Cohen's d } \\
\text { Effect Size }\end{array}$ \\
\hline \multirow{3}{*}{$\begin{array}{l}\text { Body } \\
\text { mass }\end{array}$} & \multirow{3}{*}{$\mathrm{kg}$} & Pre & $66.5 \pm 8.5$ & & & 61.2 & \pm & 6.9 & & & 70.3 & \pm & 7.8 & & \\
\hline & & Post $_{\mathrm{TOT}}$ & $66.5 \pm 8.3$ & 0.861 & 0.0000 & 61.4 & \pm & 6.8 & 0.149 & 0.0292 & 70.2 & \pm & 7.6 & 0.497 & 0.0130 \\
\hline & & Post $_{\text {WFI }}$ & $66.0 \pm 8.3$ & $<0.001 *$ & 0.0595 & 60.9 & \pm & 6.8 & 0.015 * & 0.0438 & 69.6 & \pm & 7.6 & $<0.001 *$ & 0.9089 \\
\hline \multirow{4}{*}{ TBW } & \multirow{4}{*}{$\begin{array}{l}\mathrm{L} \\
\%\end{array}$} & Pre & $39.5 \pm 6.6$ & \multirow{2}{*}{0.139} & \multirow{2}{*}{0.0314} & 33.4 & \pm & 3.4 & \multirow{2}{*}{0.076} & \multirow{2}{*}{0.0895} & 43.8 & \pm & 4.5 & \multirow{2}{*}{$0.002 *$} & \multirow{2}{*}{0.1377} \\
\hline & & Post & $39.3 \pm 6.1$ & & & 33.7 & \pm & 3.3 & & & 43.2 & \pm & 4.2 & & \\
\hline & & Pre & $59.3 \pm 4.4$ & \multirow{2}{*}{0.052} & \multirow{2}{*}{0.0719} & 54.8 & \pm & 2.1 & \multirow{2}{*}{0.180} & \multirow{2}{*}{0.0975} & 62.4 & \pm & 2.0 & \multirow{2}{*}{$<0.001$ * } & \multirow{2}{*}{0.3586} \\
\hline & & Post & $59.0 \pm 3.9$ & & & 55.0 & \pm & 2.0 & & & 61.7 & \pm & 1.9 & & \\
\hline \multirow{2}{*}{ FFM } & \multirow[b]{2}{*}{$\mathrm{kg}$} & Pre & $54.0 \pm 9.0$ & \multirow[b]{2}{*}{0.144} & \multirow[b]{2}{*}{0.0344} & 45.7 & \pm & 4.6 & \multirow[b]{2}{*}{0.058} & \multirow[b]{2}{*}{0.0652} & 59.8 & \pm & 6.1 & \multirow[b]{2}{*}{$0.002 *$} & \multirow{2}{*}{0.1175} \\
\hline & & Post & $53.7 \pm 8.4$ & & & 46.0 & \pm & 4.6 & & & 59.1 & \pm & 5.8 & & \\
\hline \multirow{4}{*}{ FM } & $\mathrm{kg}$ & Pre & $12.5 \pm 3.7$ & \multirow{2}{*}{$0.032 *$} & \multirow{2}{*}{0.1124} & 15.5 & \pm & 3.0 & \multirow{2}{*}{0.168} & \multirow{2}{*}{0.0339} & 10.5 & \pm & 2.4 & \multirow{2}{*}{$<0.001 *$} & \\
\hline & $\mathrm{kg}$ & Post & $12.9 \pm 3.4$ & & & 15.4 & \pm & 2.9 & & & 11.1 & \pm & 2.5 & & 0.2447 \\
\hline & & Pre & $19.1 \pm 6.0$ & & & 25.3 & \pm & 2.9 & & & 14.8 & \pm & 2.7 & & \\
\hline & $\%$ & Post & $19.5 \pm 5.3$ & 0.065 & 0.0704 & 24.9 & \pm & 2.8 & 0.083 & 0.1403 & 15.7 & \pm & 2.6 & $<0.001 *$ & 0.3394 \\
\hline
\end{tabular}

Values are expressed as means \pm SD. Means: difference between two dependent means; ${ }^{\wedge}$ in reference to "pre" value, effect size by $\mathrm{d}$ Cohen (0.2 to 0.5 - small effect, 0.5 to 0.8 - medium effect, 0.8 to 1.3 -large effect, $>1.3$ - very large effect); FFM-Fat Free Mass, FM-

Fat Mass, Post

* statistically significant.

Evaluation of the relationships between FI and actual FL, the TBW before training and the actual FL and between FI and TBW before training for the whole group, female and male are presented in Table 2 and Figure 2. There were no statistically significant correlations between FI and actual FL and between FI and TBW before training. However, significant correlations were observed in the whole group between actual FL $(\mathrm{mL})$ and pre-workout TBW respectively (in \%: $r=-0.64$; in litres: $r=-0.84$ ). In relationship to sex, although no significant correlations were detected in females, males showed a correlation between pre-workout TBW $(\mathrm{L})$ and actual FL $(\mathrm{mL})(\mathrm{r}=-0.73)$ (Table 3).

Table 3. Correlation between selected primary indices in the whole group, female and male.

\begin{tabular}{|c|c|c|c|c|c|c|}
\hline \multicolumn{3}{|c|}{ Variable } & \multirow{2}{*}{$\begin{array}{c}\mathbf{R} \\
-0.14\end{array}$} & \multirow{2}{*}{$\begin{array}{c}\mathbf{R}^{2} \\
0.02\end{array}$} & \multirow{2}{*}{$\frac{\mathbf{t}}{-0.55}$} & \multirow{2}{*}{$\frac{p \text {-Value }}{0.590}$} \\
\hline Fluid Intake & & All $(n=17)$ & & & & \\
\hline vs. & mL vs. L & Females $(n=7)$ & -0.41 & 0.17 & -1.02 & 0.356 \\
\hline Actual Fluids Loss & & Males $(n=10)$ & 0.17 & 0.03 & 0.48 & 0.646 \\
\hline \multirow{6}{*}{$\begin{array}{c}\text { Pre-exercise Total Body } \\
\text { Water content } \\
\text { vs. } \\
\text { Actual Fluids Loss }\end{array}$} & \multirow{3}{*}{$\%$ vs. mL } & All $(n=17)$ & -0.64 & 0.41 & -3.20 & 0.006 * \\
\hline & & Females $(n=7)$ & 0.19 & 0.04 & 0.43 & 0.683 \\
\hline & & Males $(n=10)$ & -0.35 & 0.12 & -1.05 & 0.323 \\
\hline & \multirow{3}{*}{ L vs. mL } & All $(n=17)$ & -0.84 & 0.70 & -5.90 & $<0.001 *$ \\
\hline & & Females $(n=7)$ & -0.59 & 0.35 & -1.65 & 0.161 \\
\hline & & Males $(n=10)$ & -0.73 & 0.53 & -3.01 & 0.017 * \\
\hline
\end{tabular}


Table 3. Cont.

\begin{tabular}{|c|c|c|c|c|c|c|}
\hline & & & $\mathbf{R}$ & $\mathbf{R}^{2}$ & $\mathbf{t}$ & $p$-Value \\
\hline \multirow{6}{*}{$\begin{array}{c}\text { Fluids Intake } \\
\text { vs. } \\
\text { Pre-exercise Total Body } \\
\text { Water content }\end{array}$} & \multirow{3}{*}{ mL vs. $\%$} & All $(n=17)$ & 0.17 & 0.03 & 0.68 & 0.506 \\
\hline & & Females $(n=7)$ & 0.37 & 0.14 & 0.89 & 0.416 \\
\hline & & Males $(n=10)$ & -0.14 & 0.02 & -0.40 & 0.699 \\
\hline & \multirow{3}{*}{ mL vs. $\mathrm{L}$} & All $(n=17)$ & 0.05 & 0.00 & 0.20 & 0.846 \\
\hline & & Females $(n=7)$ & 0.07 & 0.00 & 0.16 & 0.882 \\
\hline & & Males $(n=10)$ & -0.23 & 0.05 & -0.67 & 0.519 \\
\hline
\end{tabular}

Values are expressed as correlation coefficients $(\mathrm{R})$, coefficients of determination $\left(\mathrm{R}^{2}\right)$ and test statistics $(\mathrm{t}) ;{ }^{*}$ statistically significant.
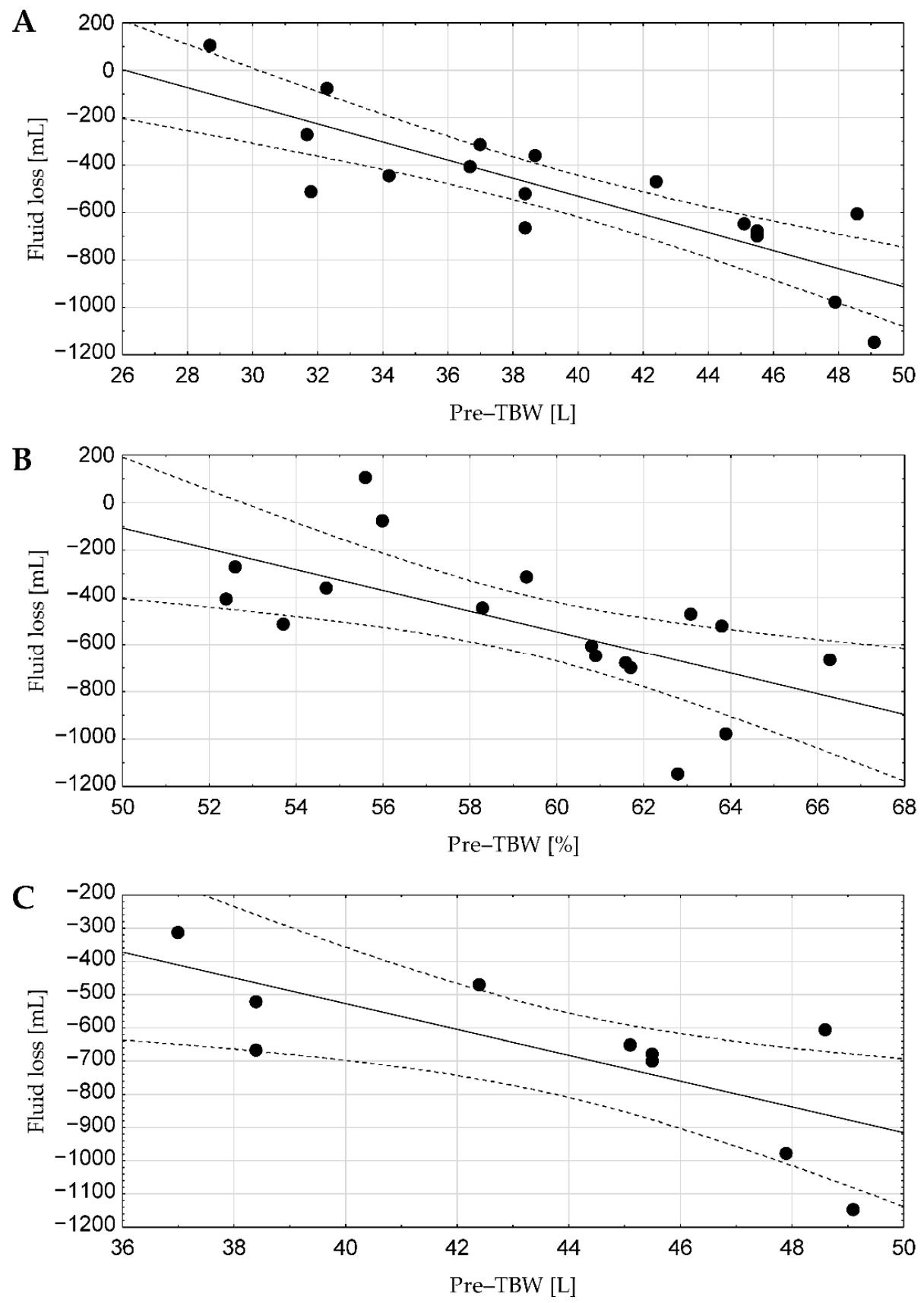

Figure 2. (A-C) present relationships between actual fluid loss and total body water content before training in the whole study group (mL vs. $\mathrm{L}(\mathbf{A})$ and $\mathrm{mL}$ vs. \% (B)), also in the group of males (mL vs. $\mathrm{L}(\mathrm{C})$ ). The black dots represent the values of the individual participants. 


\section{Discussion}

The results of the study carried out in young swimmers provide additional information and fill the scientific gap regarding FL as a result of a standard two-hour swimming training unit, taking into account the usual FI during the training, as well as changes in body composition, and selected correlations of factors that can substantially contribute to athletic performance and competition results. During that training unit, swimmers' total body water content decreased about $0.5 \%$ for females and $1.0 \%$ for males.

We registered a large effect size between gender-related FL (d: from 1.61 to 1.72; $p$ : from 0.004 to 0.006 ). This loss in the whole study group was on average $-513 \mathrm{~mL}$ (about $-284 \mathrm{~mL}$ for females and $-674 \mathrm{~mL}$ for males). Taking into account the recorded customary FI, the average body hydration status changes were about $-267 \mathrm{~mL} / \mathrm{h}$ in the whole group $(-142 \mathrm{~mL} / \mathrm{h}$ in females and $-337 \mathrm{~mL} / \mathrm{h}$ in males). These data are lower than those presented by Cox et al. [24] in a study on weight changes and spontaneous FI in water polo athletes ( 23 males) and swimmers ( 20 females and 21 males) aged between 16 and 32 years. Moreover, the quoted authors noted that, in swimmers, FL was $\sim 314 \mathrm{~mL} / \mathrm{h}$ for females and $\sim 415 \mathrm{~mL} / \mathrm{h}$ for males. However, the lower amount of FL in our studies could result from a lower intensity of muscle work during the training unit. We would like to underline that our investigations took place during the period of general macrocycle preparation, in which the efforts during the given training units are usually characterised by average intensity. Moreover, it should be noted that during training, the swimmers covered a relatively small distance- $4500 \mathrm{~m}$. Additionally, consultations with coaches suggested that during a training unit of the same duration as the analysed one (two hours), swimmers can even swim $\sim 33 \%$ longer distances. In our opinion, the FL would probably be higher than the one observed and, taking into account mathematical assumptions, if it grew proportionally, it could be about $-684 \mathrm{~mL}$ for the whole group (about $-378 \mathrm{~mL}$ for females and about $900 \mathrm{~mL}$ for males). On an hourly training basis, these values would be about $-342 \mathrm{~mL} / \mathrm{h}$ for the whole group, about $189 \mathrm{~mL} / \mathrm{h}$ for females, and about $-450 \mathrm{~mL} / \mathrm{h}$ for males, thus they would be much closer to those observed by Cox and colleagues [24].

In our study, the average FI per training unit was about $531 \mathrm{~mL}$ for the entire study group ( $\sim 469 \mathrm{~mL}$ for females and $\sim 574 \mathrm{~mL}$ for males). In this range, it corresponded on average to $69 \%$ (and $110 \%$ and $56.8 \%$, respectively) in relation to the recommendations in this field [25]. Nevertheless, the amount of fluids usually taken by swimmers had an effect on the BW of the athletes after training, which, in the case of the whole group, was comparable to that before training (in the case of females, it was on average $0.2 \mathrm{~kg}$ higher; in the case of males, it was $0.1 \mathrm{~kg}$ lower). Our results are also similar to those presented in the study of Adams et al. [21] on water balance in teenage swimmers. It can be assumed that changes in BW were insignificant (about $0.1 \pm 0.3 \mathrm{~kg}$ ) due to balanced ad libitum FI.

Therefore, taking into account the recommendations on FI by Domínguez et al. [25] concerning the nutritional needs of swimmers, indicating an optimal water/fluid intake of $150 \%$ of the amount of FL during training, the amount of fluids consumed during training in the examined athletes seems to be acceptable for both females and males. Although these values are less than about $150 \%$ of the water lost through sweat, this demand does not have to be covered during training only; it can be done after a training unit as well. It is worth noting that this is of fundamental importance, especially if athletes perform two or more training units per day, in order to start their next efforts in a state of euhydration.

Furthermore, the studied swimmers were analysed before and after the second training unit on that day. The optimal pre-training hydration status of this group is indicated by TBW values marked in the body composition analysis. Moreover, during the training of the tested swimmers, the average BW of the whole group did not change significantly after exercise (in the case of females it was even slightly higher, and in the case of males it was slightly lower). This is beneficial in practice because maintaining the state of optimal hydration allows for the effort to be carried out with maximum physiological capacity through advantageous effects on endurance performance [26] and cognitive performances [27], as well as avoiding the risk of the negative effects of dehydration that 
can be observed in athletes already with very low FL of one to two percent of BW (which may already be manifested by an increased heart rate, internal temperature or muscle glycogen usage) [28]. However, it should also be mentioned that in some cases FI may not exert a spectacular impact on some of the exercise results achieved (especially those related to physical abilities, such as power or speed) [29]. In a study of 19 swimmers aged 11 to 17, Briars et al. [29] recorded that the supply of mineral water, isotonic drinks or lack of FI, respectively, did not improve specific swimming performance (results of $50 \mathrm{~m}$ sprints), although during a training unit in water (lasting over $105 \mathrm{~min}$ ) among swimmers who did not receive any fluids, a reduction in TBW of at least a $0.42 \%$ was observed.

In addition, the results obtained in our study indicate that while maintaining the current practice of hydration, no negative changes resulting from excessive FL and/or dehydration should be observed in the examined young swimmers. However, it is worth recalling that the performed training unit was neither high in volume nor in intensity. In this respect, it seems reasonable to assume that in case of swimmers who had swum longer distance and/or exercised with higher intensity, the reduction of hydration could have been more elevated than reported in our study. Furthermore, as indicated in another study [21], water has a much higher thermal capacity, thermal conductivity and density than air, making the heat exchange much faster. It seems that these factors may affect the rate of thermoregulation in water, which may additionally vary with water temperature [30]. Therefore, given that pool water temperatures range from 25 to $28^{\circ} \mathrm{C}$ [2], it is possible that a different water temperature than that observed in our study $\left(27^{\circ} \mathrm{C}\right)$ could cause a different rate of FL.

Simultaneously, it is worth briefly noting that the FL during training performed in a land environment among athletes of other disciplines was also analysed. The results of Broad et al. [31] show that the average FL during training in summer was about $1371 \mathrm{~mL} / \mathrm{h}$ for basketball players and $985 \mathrm{~mL} / \mathrm{h}$ for football players. Although training in a water environment, according to the opinions of some coaches and athletes, apparently seems to have less impact on the disturbance of optimal hydration of swimmers than the training of players of other disciplines performed in a land environment, it is still fundamental to properly and regularly hydrate swimmers before, during and after training, as emphasized by the authors of the current recommendations [25]. This thesis also seems to be confirmed by the important relationship observed in this study between the TBW before training and the actual FL in young swimmers (in the whole group and the group of males), where higher TBW correlated with higher FL during exercise. However, no correlation between the TBW before training and actual FL was observed in females. This may be due to a slightly smaller number of females in the study group and may also hypothetically suggest that they were training in a state of suboptimal hydration, as this state results in a lower FL through sweat for thermoregulation than in a state of optimal hydration [32]. Moreover, our investigation was carried out during the second training unit of the day, which could have affected the swimmers' hydration state before the second training. A valuable indicator that would help to assess the hydration status before the training would be the evaluation of osmolality and urinary-specific gravity [33]. To confirm the reasonableness of these proceedings, Adams et al. [21], using these indicators, have recorded that $67 \%$ of swimmers started their first training unit in an inadequate state of hydration. For these reasons, we are convinced that regular body composition monitoring during both the preparatory and competitive season should be recommended as a useful tool to support athletic training.

Although it may be puzzling to note the recorded increase in the fat mass of the swimmers tested (on average before and after training, respectively: $\sim 10.5 \mathrm{~kg}$ vs. $\sim 11.1 \mathrm{~kg}$ in the case of males, and $\sim 12.5 \mathrm{~kg}$ vs. $\sim 12.9 \mathrm{~kg}$ in the whole group), according to the authors, the reason for such results lies in the accuracy of the applied measurement methods (BIA). As a result of medium- and high-intensity physical exercise, the value of the measured impedance changes, which in turn leads to a disruption in repeatability and a decrease in the accuracy of the test method. Consequently, results show a significant measurement error (values before vs. after exercise). Moreover, the change in hydration itself significantly 
affects the FFM and FM indications based on the bioimpedance method. This problem has been described in more detail in a study by Dehghan and Merchant [34] on the accuracy of electrical bioimpedance in human population studies and has also been extensively raised in studies using bioimpedance analysis to determine body composition in athletes $[35,36]$. Nevertheless, using bioimpedance analysis for measuring body water changes and fat-free mass can be a useful method that confirms Utter and Lambeth's study regarding evaluation of the accuracy of multifrequency bioelectrical impedance analysis on body composition in high school wrestlers [37] and seems to be easier and more practical for the coach and athletes than other methods such as evaluation of osmolality and urinary-specific gravity. However, with this method, strict assurance of the recommended measurement conditions is essential.

Finally, we would also like to point out some limitations of our study, which should be taken into account in the interpretation of the presented results. Although well-selected methods of measurement and analysis have been used, some limitations should be mentioned here, such as the small size of the study group (especially female $(n=7))$ and the body composition analysis methods (restrictions related to, e.g., the risk of measurement artifacts due to a gravitational effect on body fluids in a standing position, potential difficulties with the one-way comparison of the results with other BIA analysers (different BIA technologies and frequencies may produce different outputs), dependence of the final body composition value on the equation formulas used, and possibility of impedance influenced by exercise or beverage intake [38-40]). Furthermore, the possibility of interpretation being limited to the specific protocol of the training unit (the influence of exercise work intensity and environmental conditions, and, as we described above, that our studies were carried out before and after the second training unit on that day), the lack of studies on specific hydration markers (such as osmolality and urinary-specific gravity) [33], and the lack of possibility to measure the amount of water that could be absorbed by the skin. Interestingly, the latter aspect may be clinically relevant, as it was noted many years ago that by simply immersing the body in water, up to about $400 \mathrm{~mL}$ of water can be absorbed through the skin in one hour [41]. Furthermore, more recent studies involving swimmers have similarly indicated that this phenomenon may affect the final results [29], which is indirectly confirmed by the observations in our study in one of the swimmers, whose BW increased by $300 \mathrm{~g}$ after training, despite her consumption of only $198 \mathrm{~mL}$ of fluids.

The authors would like to underline that the final results may also be affected by the difficulty of making a meaningful assessment of the amount of water that may be accidentally swallowed in the course of the field study of swimming. Breaststroke, butterfly and freestyle swimming, where the exhalation takes place under water and the inhalation must take place very quickly (when the swimmer's mouth is above the water surface for a very short time), may lead to the involuntary swallowing of water [42]. It is worth noting that a lower BW after training can also result to a small extent from depletion of glycogen reserves. Its content in the human body is about $600 \mathrm{~g}$, most of which is located in the muscles [43], and as a result of intensive and long-term physical effort, the content of glycogen in active muscle cells may decrease by up to about $10 \%$ of the initial values [44]. Nonetheless, at the same time, it should be pointed out that undeniable advantages of our study are a homogeneous group of analysed subjects, as well as the fact that field study measurements were conducted during customary training in identical conditions using the same certified equipment, and with precise monitoring of the fluids actually consumed, the distance travelled, and changes in BW, FL and TBW.

\section{Conclusions}

The present study indicates a relationship between fluid loss and pre-training total body water content and that swimming training in an aquatic environment is associated with fluid loss that seems slightly lower than in a land environment. However, there is also a risk of dehydration in swimmers, especially when they train at a higher volume and intensity, or at a higher temperature; therefore, it is important to pay particular attention 
to effective hydration procedures during training units, taking into account all external factors, to prevent its negative effects on health and performance.

Author Contributions: Conceptualization, D.W. and E.Ś.; methodology, D.W. and E.Ś.; investigation, D.W. and E.S.; data curation, D.W., J.M. and E.S.; writing-original draft preparation, D.W. and K.D.-M.; writing-review and editing, E.Ś. and K.D.-M.; visualization, D.W., J.M. and K.D.-M.; supervision, K.D.-M. All authors have read and agreed to the published version of the manuscript.

Funding: This research received no external funding.

Institutional Review Board Statement: Ethical review and approval were waived for this study, due to the non-interventional and non-invasive status of this observational preliminary study.

Informed Consent Statement: Informed consent was obtained from all subjects involved in the study.

Data Availability Statement: The datasets used and/or analysed during the current study are available from the corresponding author on reasonable request.

Acknowledgments: We thank athletes and coaches for their cooperation.

Conflicts of Interest: The authors declare no conflict of interest.

\section{References}

1. Mallon, B.; Widlund, T. The 1896 Olympic Games: Results for All Competitors in All Events, with Commentary; McFarland: Jefferson, NC, USA, 2009.

2. Fédération Internationale de Natation. FINA Facilities Rules 2017-2021; Fédération Internationale de Natation: Lausanne, Switzerland, 2017.

3. Jimenez, C.; Regnard, J.; Robinet, C.; Mourot, L.; Gomez-Merino, D.; Chennaoui, M.; Jammes, Y.; Dumoulin, G.; Desruelle, A.V.; Melin, B. Whole body immersion and hydromineral homeostasis: Effect of water temperature. Eur. J. Appl. Physiol. 2010, 108, 49-58. [CrossRef]

4. Baker, L.B. Physiology of sweat gland function: The roles of sweating and sweat composition in human health. Temperature 2019, 6, 211-259. [CrossRef] [PubMed]

5. Popkin, B.M.; D'Anci, K.E.; Rosenberg, I.H. Water, hydration, and health. Nutr. Rev. 2010, 68, 439-458. [CrossRef]

6. Kavouras, S.A.; Anastasiou, C.A. Water physiology. Nutr. Today 2010, 45 (Suppl. 6), S27-S32. [CrossRef]

7. Visser, M.; Gallagher, D.; Deurenberg, P.; Wang, J.; Pierson, R.N., Jr.; Heymsfield, S.B. Density of fat-free body mass: Relationship with race, age, and level of body fatness. Am. J. Physiol. 1997, 272, E781-E787. [CrossRef] [PubMed]

8. Altman, P.L; Katz, D.D. Blood and Other Body Fluids; Federation of American Societies for Experimental Biology: Washington, DC, USA, 1961.

9. Watso, J.C.; Farquhar, W.B. Hydration status and cardiovascular function. Nutrients 2019, 11, 1866. [CrossRef] [PubMed]

10. Manz, F. Hydration and disease. J. Am. Coll. Nutr. 2007, 26 (Suppl. 5), 535S-541S. [CrossRef] [PubMed]

11. Campa, F.; Piras, A.; Raffi, M.; Trofè, A.; Perazzolo, M.; Mascherini, G.; Toselli, S. The effects of dehydration on metabolic and neuromuscular functionality during cycling. Int. J. Environ. Res. Public Health 2020, 17, 1161. [CrossRef]

12. González-Alonso, J.; Calbet, J.A.L.; Nielsen, B. Metabolic and thermodynamic responses to dehydration-induced reductions in muscle blood flow in exercising humans. J. Physiol. 1999, 520 Pt 2, 577-589. [CrossRef]

13. Logan-Sprenger, H.M.; Heigenhauser, G.J.F.; Jones, G.L.; Spriet, L.L. The effect of dehydration on muscle metabolism and time trial performance during prolonged cycling in males. Physiol. Rep. 2015, 3, e12483. [CrossRef] [PubMed]

14. Nybo, L.; Jensen, T.; Nielsen, B.; González-Alonso, J. Effects of marked hyperthermia with and without dehydration on $\mathrm{VO}(2)$ kinetics during intense exercise. J. Appl. Physiol. 2001, 90, 1057-1064. [CrossRef]

15. Durkalec-Michalski, K.; Nowaczyk, P.M.; Podgórski, T.; Kusy, K.; Osiński, W.; Jeszka, J. Relationship between body composition and the level of aerobic and anaerobic capacity in highly trained male rowers. J. Sports Med. Phys. Fit. 2019, 59, 1526-1535. [CrossRef] [PubMed]

16. Durkalec-Michalski, K.; Gościańska, I.; Jeszka, J. Does conventional body weight reduction decreasing anaerobic capacity of boxers in the competition period? Arch. Budo 2015, 11, 251-258.

17. Murray, R. Fluid needs in hot and cold environments. Int. J. Sport Nutr. 1995, 5 (Suppl. 1), S62-S73. [CrossRef]

18. Kenney, E.L.; Long, M.W.; Cradock, A.L.; Gortmaker, S.L. Prevalence of Inadequate Hydration among US Children and Disparities by Gender and Race/Ethnicity: National Health and Nutrition Examination Survey, 2009-2012. Am. J. Public Health 2015, 105, e113-e118. [CrossRef] [PubMed]

19. Aphamis, G.; Stavrinou, P.S.; Andreou, E.; Giannaki, C.D. Hydration status, total water intake and subjective feelings of adolescents living in a hot environment, during a typical school day. Int. J. Adolesc. Med. Health 2019. [CrossRef]

20. Arnaoutis, G.; Kavouras, S.A.; Angelopoulou, A.; Skoulariki, C.; Bismpikou, S.; Mourtakos, S.; Sidossis, L.S. Fluid balance during training in elite young athletes of different sports. J. Strength Cond. Res. 2015, 29, 3447-3452. [CrossRef]

21. Adams, J.D.; Kavouras, S.A.; Robillard, J.I.; Bardis, C.N.; Johnson, E.C.; Ganio, M.S.; McDermott, B.P.; White, M.A. Fluid balance of adolescent swimmers during training. J. Strength Cond. Res. 2016, 30, 621-625. [CrossRef] [PubMed] 
22. Savoie, F.A.; Kenefick, R.W.; Ely, B.R.; Cheuvront, S.N.; Goulet, E.D.B. Effect of hypohydration on muscle endurance, strength, anaerobic power and capacity and vertical jumping ability: A meta-analysis. Sports Med. 2015, 45, 1207-1227. [CrossRef] [PubMed]

23. Cohen, J. Statistical Power Analysis for the Behavioral Sciences, 2nd ed.; Routledge Academic: New York, NY, USA, $1988 ;$ ISBN 9780203771587.

24. Cox, G.R.; Broad, E.M.; Riley, M.D.; Burke, L.M. Body mass changes and voluntary fluid intakes of elite level water polo players and swimmers. J. Sci. Med. Sport 2002, 5, 183-193. [CrossRef]

25. Domínguez, R.; Jesús-Sánchez-Oliver, A.; Cuenca, E.; Jodra, P.; da Silva, S.F.; Mata-Ordóñez, F. Nutritional needs in the professional practice of swimming: A review. J. Exerc. Nutr. Biochem. 2017, 21, 1-10. [CrossRef]

26. Casa, D.J.; Stearns, R.L.; Lopez, R.M.; Ganio, M.S.; McDermott, B.P.; Yeargin, S.W.; Yamamoto, L.M.; Mazerolle, S.M.; Roti, M.W.; Armstrong, L.E.; et al. Influence of hydration on physiological function and performance during trail running in the heat. J. Athl. Train. 2010, 45, 147-156. [CrossRef]

27. Zhang, J.; Zhang, N.; Du, S.; He, H.; Xu, Y.; Cai, H.; Guo, X.; Ma, G. The effects of hydration status on cognitive performances among young adults in Hebei, China: A randomized controlled trial (RCT). Int. J. Environ. Res. Public Health 2018, 15, 1477. [CrossRef]

28. Ayotte, D.; Corcoran, M.P. Individualized hydration plans improve performance outcomes for collegiate athletes engaging in in-season training. J. Int. Soc. Sports Nutr. 2018, 15, 27. [CrossRef] [PubMed]

29. Briars, G.L.; Gordon, G.S.; Lawrence, A.; Turner, A.; Perry, S.; Pillbrow, D.; Walston, F.E.; Molyneux, P. Swim drink study: A randomised controlled trial of during-exercise rehydration and swimming performance. BMJ Paediatr. Open 2017, 1, e000075. [CrossRef]

30. Tikuisis, P.; Gonzalez, R.R.; Pandolf, K.B. Thermoregulatory model for immersion of humans in cold water. J. Appl. Physiol. 1988, 64, 719-727. [CrossRef] [PubMed]

31. Broad, E.; Burke, L.; Cox, G.; Heeley, P.; Riley, M. Body weight changes and voluntary fluid intakes during training and competition sessions in team sports. Int. J. Sport Nutr. 1996, 6, 307-320. [CrossRef]

32. Sawka, M.N.; Montain, S.J.; Latzka, W.A. Hydration effects on thermoregulation and performance in the heat. Comp. Biochem. Physiol. Part A Mol. Integr. Physiol. 2001, 128, 679-690. [CrossRef]

33. Sawka, M.N.; Burke, L.M.; Eichner, E.R.; Maughan, R.J.; Montain, S.J.; Stachenfel, N.S. American College of Sports Medicine position stand. Exercise and fluid replacement. Med. Sci. Sports Exerc. 2007, 39, 377-390. [CrossRef]

34. Dehghan, M.; Merchant, A.T. Is bioelectrical impedance accurate for use in large epidemiological studies? Nutr. J. 2008, 9, 26. [CrossRef] [PubMed]

35. Reis, J.F.; Matias, C.N.; Campa, F.; Morgado, J.P.; Franco, P.; Quaresma, P.; Almeida, N.; Curto, D.; Toselli, S.; Monteiro, C.P. Bioimpedance vector patterns changes in response to swimming training: An ecological approach. Int. J. Environ. Res. Public Health 2002, 17, 4851. [CrossRef]

36. Campa, F.; Matias, C.; Gatterer, H.; Toselli, S.; Koury, J.C.; Andreoli, A.; Melchiorri, G.; Sardinha, L.B.; Silva, A.M. Classic Bioelectrical Impedance Vector Reference Values for Assessing Body Composition in Male and Female Athletes. Int. J. Environ. Res. Public Health 2019, 16, 5066. [CrossRef]

37. Utter, A.C.; Lambeth, P.G. Evaluation of multifrequency bioelectrical impedance analysis in assessing body composition of wrestlers. Med. Sci. Sports Exerc. 2010, 42, 361-367. [CrossRef] [PubMed]

38. Jaffrin, M.Y.; Kieffer, R.; Moreno, M.V. Evaluation of a foot-to-foot impedance meter measuring extracellular fluid volume in addition to fat-free mass and fat tissue mass. Nutrition 2005, 21, 815-824. [CrossRef] [PubMed]

39. Medrano, G.; Eitner, F.; Walter, M.; Leonhardt, S. Model-based correction of the influence of body position on continuous segmental and hand-to-foot bioimpedance measurements. Med. Biol. Eng. Comput. 2010, 48, 531-541. [CrossRef]

40. Olier, C.J.; Irurtia, A.; Jemni, M.; Marginet, C.M.; García, F.R.; Rodríguez, F.A. Bioelectrical Impedance Vector Analysis (BIVA) in Sport and Exercise: Systematic Review and Future Perspectives. PLoS ONE 2018, 13, e0197957. [CrossRef]

41. Scheuplein, R.J.; Blank, I.H. Permability of the skin. Physiol. Rev. 1971, 51, 702-747. [CrossRef]

42. Dorevitch, S.; Panthi, S.; Huang, Y.; Li, H.; Michalek, A.M.; Pratap, P.; Wroblewski, M.; Liu, L.; Scheff, P.A.; Li, A. Water ingestion during water recreation. Water Res. 2011, 45, 2020-2028. [CrossRef]

43. Hargreaves, M. The metabolic systems: Carbohydrate metabolism. In ACSM's Advanced Exercise Physiology, 2nd ed.; Farrell, P., Ed.; Lippincott Williams \& Wilkins: Philadelphia, PA, USA, 2012; pp. 379-391.

44. Burke, L.M.; van Loon, L.J.; Hawley, J.A. Post-exercise muscle glycogen resynthesis in humans. J. Appl. Physiol. 2017, $122,1055-1067$. [CrossRef] 